\title{
Experimental Verification of a Battery Energy Storage System for Integration with Photovoltaic Generators
}

\author{
Rajkiran Singh, ${ }^{1}$ Seyedfoad Taghizadeh, ${ }^{1}$ Nadia M. L. Tan, ${ }^{1}$ and Saad Mekhilef ${ }^{2}$ \\ ${ }^{1}$ Department of Electrical Power Engineering, Universiti Tenaga Nasional, Selangor, Malaysia \\ ${ }^{2}$ Power Electronics and Renewable Energy Research Laboratory (PEARL), Department of Electrical Engineering, \\ University of Malaya, Kuala Lumpur, Malaysia \\ Correspondence should be addressed to Nadia M. L. Tan; nadia@uniten.edu.my
}

Received 26 June 2016; Revised 20 September 2016; Accepted 22 December 2016; Published 24 January 2017

Academic Editor: Antonio J. Marques Cardoso

Copyright (c) 2017 Rajkiran Singh et al. This is an open access article distributed under the Creative Commons Attribution License, which permits unrestricted use, distribution, and reproduction in any medium, provided the original work is properly cited.

\begin{abstract}
This paper presents the experimental verification of a $2 \mathrm{~kW}$ battery energy storage system (BESS). The BESS comprises a full-bridge bidirectional isolated dc-dc converter and a PWM converter that is intended for integration with a photovoltaic (PV) generator, resulting in leveling of the intermittent output power from the PV generator at the utility side. A phase-shift controller is also employed to manage the charging and discharging operations of the BESS based on PV output power and battery voltage. Moreover, a current controller that uses the $d-q$ synchronous reference frame is proposed to regulate the dc voltage at the high-voltage side (HVS) to ensure that the voltage ratio of the HVS with low-voltage side (LVS) is equivalent to the transformer turns ratio. The proposed controllers allow fast response to changes in real power requirements and results in unity power factor current injection at the utility side. In addition, the efficient active power injection is achieved as the switching losses are minimized. The peak efficiency of the bidirectional isolated dc-dc converter is measured up to $95.4 \%$ during battery charging and $95.1 \%$ for battery discharging.
\end{abstract}

\section{Introduction}

Current grid codes for low-voltage grid-connected PV systems consider a low PV penetration and in many countries stipulate the regulation for anti-islanding and total harmonic distortion of injected current to be less than $5 \%$. A high penetration of PV systems will require strict adherence to the grid codes because a large amount of varying active power will result in frequency variations and eventually instability of the power grid. Therefore, the integration of battery energy storage system, a type of high energy density storage device, is needed to level the output power from PV generators. Moreover, future grid codes are expected to include the fault ride-through (FRT) capability and reactive power injection of the PV systems [1]. Battery energy storage systems could be employed to absorb active power from PV during the FRT conditions.

A bidirectional isolated $\mathrm{dc}-\mathrm{dc}$ converter with highfrequency galvanic isolation is one of the technologies that enables the integration of energy storage devices such as batteries and electric double-layer capacitors to the utility grid [2-6]. The bidirectional operation of the converter easily charges and discharges energy storage devices. Moreover, the high-frequency galvanic isolation increases the power density and the reliability of the energy storage system. The efficiency of the bidirectional isolated dc-dc converter has improved since the converter was introduced in 1991 [7]. At that time, the first generation of IGBT suffered from high switching losses. The performance of the latest-generation IGBT improved in device switching losses. Furthermore, superjunction MOSFET has a low on-state resistance $R_{\mathrm{DS}[\mathrm{ON}]}$ that further reduces conduction loss of the switching device [2].

A $6 \mathrm{~kW}$, a $10 \mathrm{~kW}$, and a $100 \mathrm{~kW}$ bidirectional isolated dc-dc converter achieved maximum efficiency of $96.9 \%$ [3], 97.4\% [4], and 98.7\% [5], respectively. The authors of [5] showed that, with the usage of silicon carbide MOSFETs, the performance of the bidirectional isolated $\mathrm{dc}$-dc converter is greatly improved as compared to the dc-dc converter using siliconbased switching devices. The $\mathrm{dc}-\mathrm{dc}$ converter operation is 


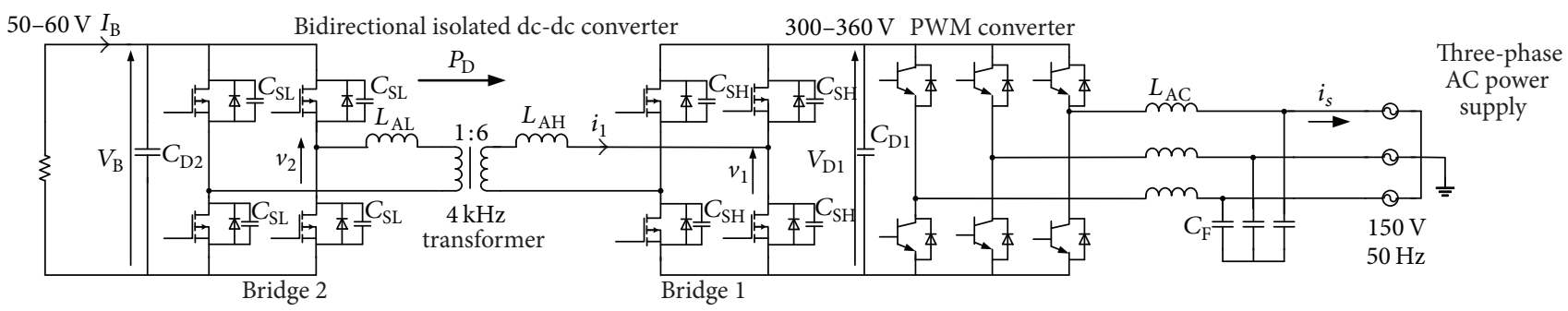

FIGURE 1: The experimental configuration of the BESS in charging mode. $L_{\mathrm{AC}}=5 \mathrm{mH}(7.85 \%)$ and $C_{\mathrm{F}}=1 \mu \mathrm{F}$, on a three-phase $150 \mathrm{~V}, 2 \mathrm{~kW}$, and $50 \mathrm{~Hz}$ base.

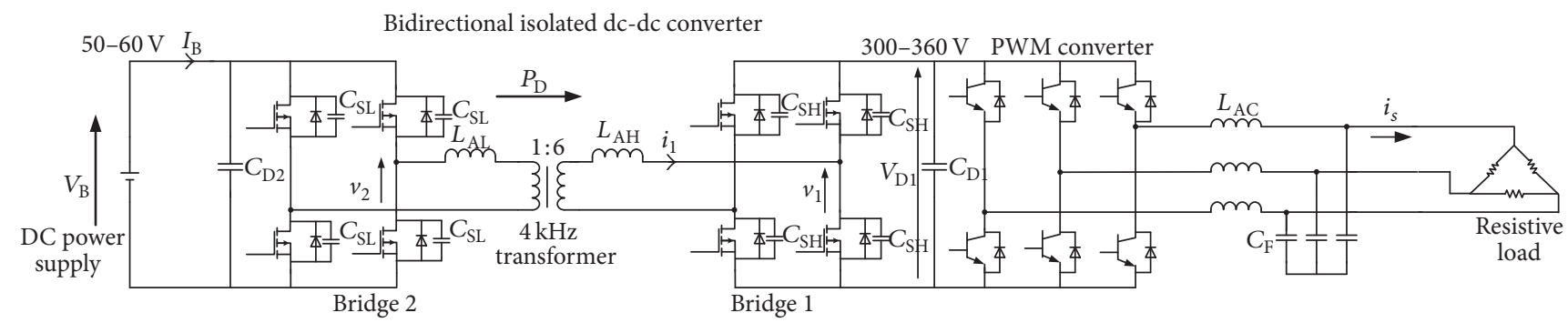

FIGURE 2: The experimental configuration of the BESS in discharging mode. $L_{\mathrm{AC}}=5 \mathrm{mH}(7.85 \%)$ and $C_{\mathrm{F}}=1 \mu \mathrm{F}$, on a three-phase $150 \mathrm{~V}$, $2 \mathrm{~kW}$, and $50 \mathrm{~Hz}$ base.

optimum only when the voltage ratio of the HVS and LVS is equal to the turn ratio of the transformer. Otherwise, the circulating current will be high, leading to an increase in switching loss due to high peak switching current and high turn-off overvoltage across the semiconductor switches. The circulating current should be minimized so that the efficiency of the converter is maintained high in applications with a broad range of operating voltage. Therefore, a reliable control system is required to adjust the voltage of HVS with respect to the voltage of LVS of the converter so that the voltage ratio of the HVS with LVS is close to the transformer turns ratio.

This paper describes a battery energy storage system (BESS) that consists of a battery unit, a bidirectional isolated dc-dc converter, and a PWM converter that can be applied to regulate the output power of a PV system. This paper verifies the feasibility of operating a $2 \mathrm{~kW}$ BESS that responds the changes of a varying PV output power. In order to achieve this purpose, a current controller that uses $d-q$ synchronous reference and also a phase-shift controller are employed. The main function of the current controller is to regulate the voltage at HVS to maintain the voltage ratio of the HVS with LVS equal to the transformer turns ratio. The phase-shift controller is also employed to control the charging and discharging modes of the battery based on PV output power and battery voltage. Consequently, the operation of the both control systems maintains the gridinjected power at a constant value. Reference [8] has shown only the simulation results of the proposed system. This paper aims to validate the proposed system by the construction of a laboratory prototype and to show that the controllers have fast response and are feasible to be integrated with a PV system.

\section{Experimental System}

Figures 1 and 2 present the experimental circuit of the charging and discharging modes of the proposed BESS, respectively. The system consists of a three-phase PWM converter, a $2 \mathrm{~kW}$ bidirectional isolated dc-dc converter, and a three-phase resistive load bank. The PWM converter is connected at ac side with a $150 \mathrm{~V}, 50 \mathrm{~Hz}$ power supply through ac-link inductors $L_{\mathrm{AC}}$ and filter capacitors $C_{\mathrm{F}}$. The proposed operating voltage of the battery, $V_{\mathrm{B}}$, varies between $50 \mathrm{~V}$ and $60 \mathrm{~V}$, and at the HVS, $V_{\mathrm{D} 1}$ is regulated between $300 \mathrm{~V}$ and $360 \mathrm{~V}$ to adjust the ratio HVS and LVS close to the transformer turns ratio. In Figure 1, a single-phase resistive load bank is used to represent the battery bank that is being charged. In Figure 2, a three-phase resistive load is connected in delta configuration at the ac side to verify the BESS in the discharging mode. Table 1 summarizes the system parameters.

The BESS is sized for active power injection of up to $2 \mathrm{~kW}$. The power transfer, $P_{\mathrm{D}}$, of the BESS can easily be controlled by adjusting the phase-shift angle $\delta$ between two ac voltages $v_{1}$ and $v_{2}$ and it is expressed as

$$
P_{\mathrm{D}}=\frac{V_{\mathrm{D} 1} V_{\mathrm{B}}}{\omega L} \delta\left(1-\frac{|\delta|}{\pi}\right),
$$

where $V_{\mathrm{D} 1}$ is the voltage at HVS, $V_{\mathrm{B}}$ is the battery voltage, $\omega$ is the angular switching frequency, and $L$ is the total inductance including the leakage inductance of the transformer and auxiliary inductances referring to the high-voltage side. The dc-dc converter is operating in charging mode when voltage $v_{1}$ leads voltage $v_{2}$. During the charging mode, $\delta$ is denoted as positive. When operating in the discharging mode, voltage $v_{2}$ leads voltage $v_{1}$, and $\delta$ is denoted as negative. 


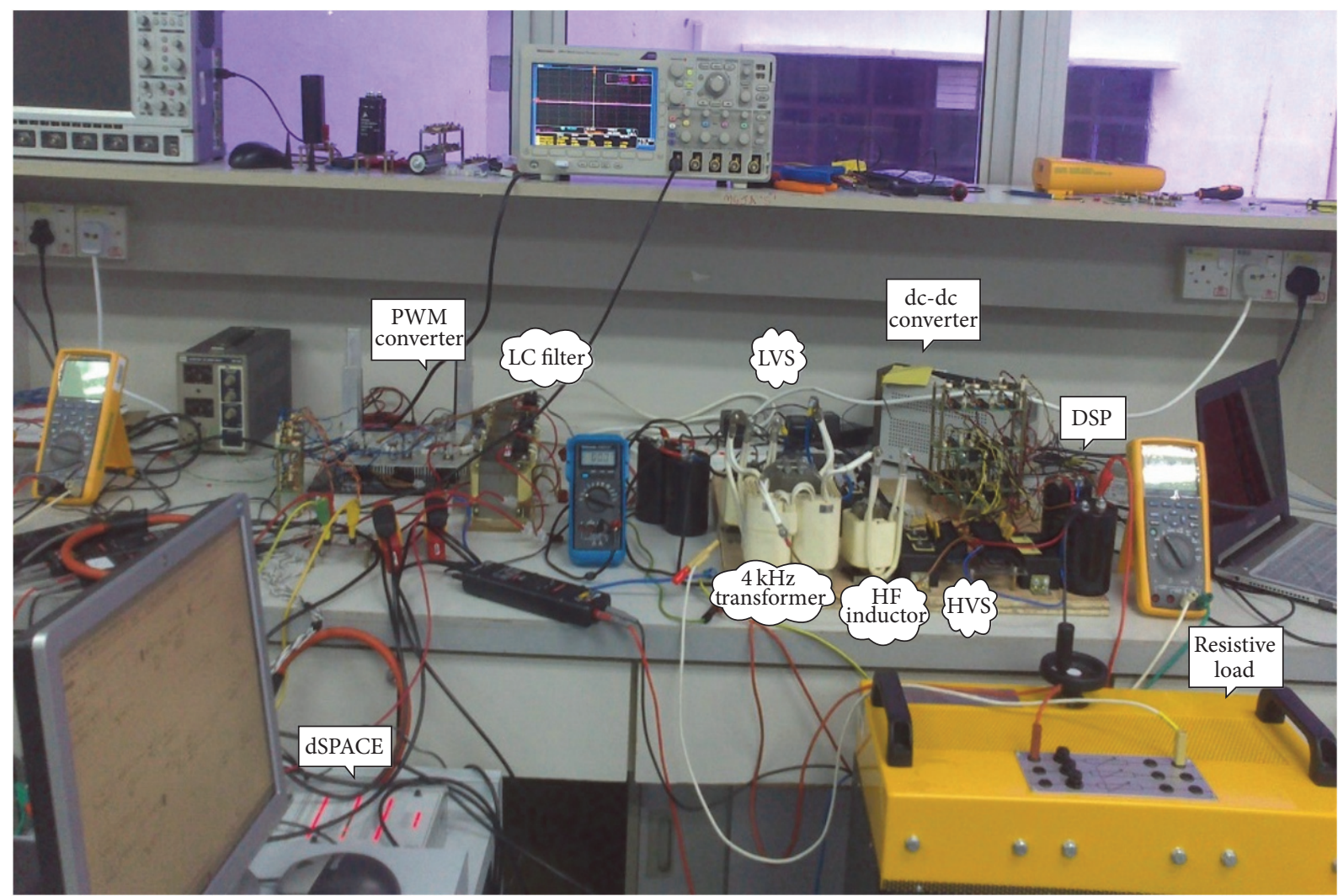

Figure 3: Photo of the experimental setup at the laboratory.

TABLE 1: Circuit parameters of the bidirectional isolated dc-dc converter.

\begin{tabular}{lcc}
\hline Rated power & $P_{\mathrm{D}}$ & $2 \mathrm{~kW}$ \\
\hline Transformer turn ratio & $N$ & $6: 1$ \\
Auxiliary inductor (HVS) & $L_{\mathrm{AH}}$ & $40 \mu \mathrm{H}(1.55 \%)$ \\
Snubber capacitor (HVS) & $C_{\mathrm{SH}}$ & $10 \mathrm{nF}$ \\
DC capacitor (HVS) & $C_{\mathrm{D} 1}$ & $2 \mathrm{mF}$ \\
Auxiliary inductor (LVS) & $L_{\mathrm{AL}}$ & $40 \mu \mathrm{H}(55.83 \%)$ \\
Snubber capacitor (LVS) & $C_{\mathrm{SL}}$ & $150 \mathrm{nF}$ \\
DC capacitor (LVS) & $C_{\mathrm{D} 2}$ & $9.6 \mathrm{mF}$ \\
Switching frequency & $f$ & $4 \mathrm{kHz}$ \\
\hline
\end{tabular}

HVS is based on $360 \mathrm{~V}, 4 \mathrm{kHz}$, and $2 \mathrm{~kW}$.

LVS is based on $60 \mathrm{~V}, 4 \mathrm{kHz}$, and $2 \mathrm{~kW}$.

Bridge 1 consists of four $600 \mathrm{~V}, 40$ A superjunction MOSFETs (TK40J60U). A film capacitor $C_{\mathrm{SH}}$ is connected in parallel with each of the superjunction MOSFETs to achieve zero-voltage turn-on and to minimize turn-off overvoltage across the switching devices. The on-state resistance, $R_{\mathrm{DS}(\mathrm{ON})}$, is as low as $65 \mathrm{~m} \Omega$.

Bridge 2 consists of four $100 \mathrm{~V}, 200 \mathrm{~A}$ superjunction MOSFETs (IXFN200N10P). $R_{\mathrm{DS}(\mathrm{ON})}$ is as low as $7.5 \mathrm{~m} \Omega$. A film capacitor $C_{\mathrm{SL}}$ is connected in parallel with each of the four MOSFETs to reduce its switching loss and to damp out any overvoltage.
The PWM converter consists of six $600 \mathrm{~V}, 20$ A Field Stop IGBTs (FGH20N60UFD). The saturation voltage is as low as $1.8 \mathrm{~V}$. The IGBTs have internal parallel diodes.

During the experiment, a three-phase portable power supply [KOSIJAYA, model: KA19530] was used for supplying the three-phase voltage. A real-time interface system dSPACE with DS1104 control card, which consists of Texas Instruments TMS320F240 subprocessor and the Power PC $603 \mathrm{e} / 250 \mathrm{MHz}$ main processor, is used for implementing the proposed current controller. This dSPACE control desk works together with MathWorks MATLAB/Simulink R2011b real-time workshop and real-time interface (RTI) control cards to implement the proposed PWM controller. Another real-time system, Texas Instrument TMS F28335 controller board, is used as the controller of the bidirectional isolated dc-dc converter. Figure 3 presents the photo of the actual experiment setup for battery charging. Further details on the implementation of the controllers are presented in Section 3.

\section{Control System}

Figure 4 presents the overall control system of the proposed BESS. Even though the control system has been presented in [8], it is explained in this paper for the sake of completeness and easy referencing. The controller is designed to regulate the power at the low-frequency ac side or the so-called "point of common coupling (PCC)" of the dc-dc converter at $2 \mathrm{~kW}$. The phase-shift controller monitors the output power of PV, 


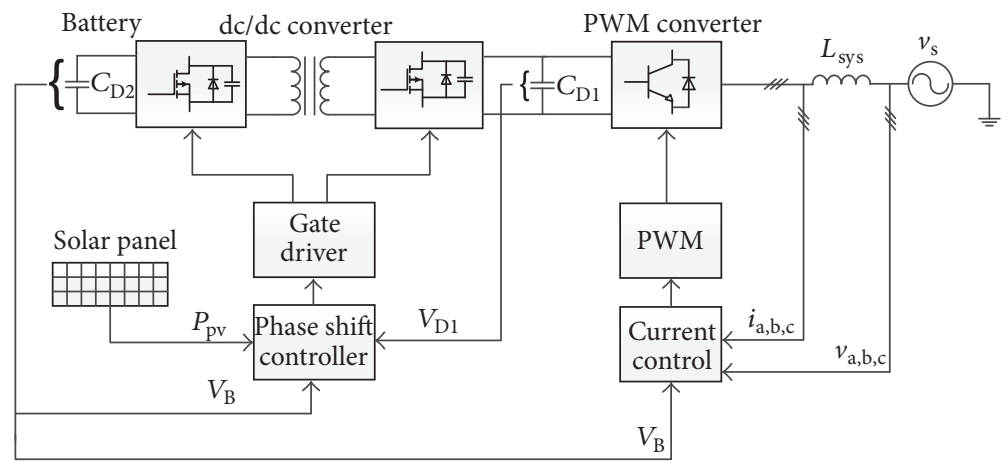

FIGURE 4: Configuration of the proposed control system.

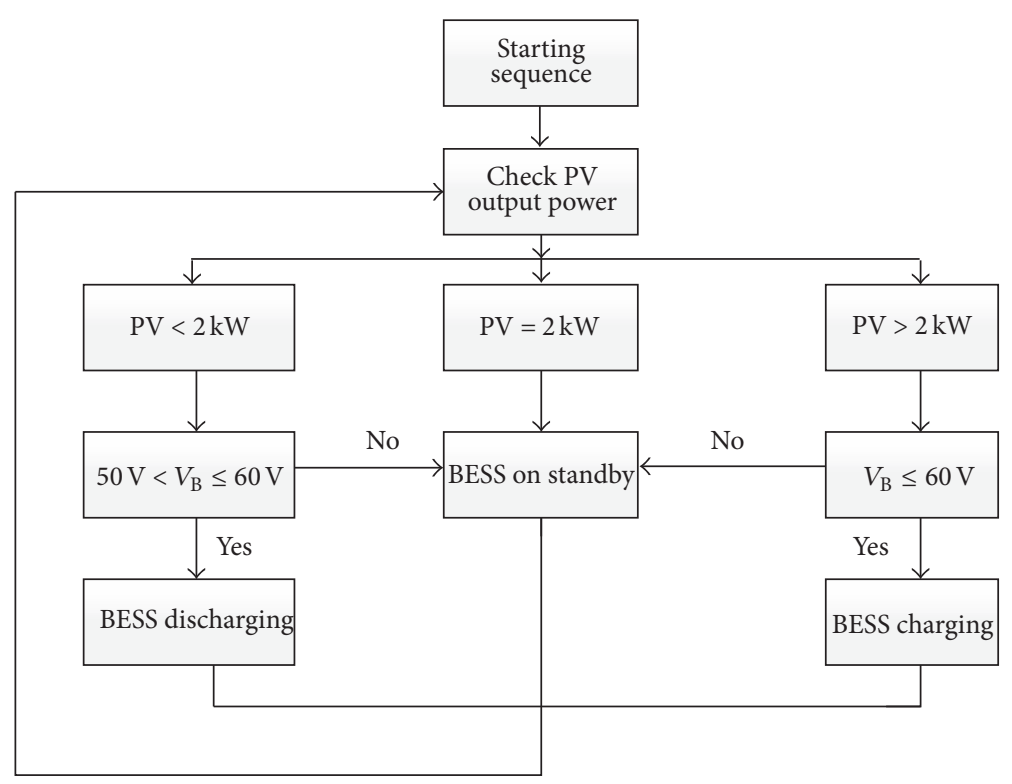

FIGURE 5: Determination of the three BESS operating modes.

$P_{\mathrm{PV}}$, to determine the desired output power from the BESS such that

$$
P_{\mathrm{BESS}}=P_{\mathrm{PCC}}-P_{\mathrm{PV}} .
$$

The controller also considers the battery voltage, $V_{\mathrm{B}}$, and the HVS dc-link voltage, $V_{\mathrm{D} 1}$. Then it determines the required phase-shift angle, $\delta$, needed to level the PV output power by charging or discharging the battery. Note that, in the experiment, the PV output power is arbitrary and the modeling of PV generation system is outside the scope of this paper.

Figure 5 shows the typical operating modes of a BESS, which are the charging, discharging, and standby modes. When the PV output power is less than $2 \mathrm{~kW}$, the controller checks the battery voltage. If the battery voltage is between $50 \mathrm{~V}$ and $60 \mathrm{~V}\left(50 \mathrm{~V}<V_{\mathrm{B}} \leq 60 \mathrm{~V}\right)$, the BESS is operated in the discharging mode. When the PV output power is more than $2 \mathrm{~kW}$, the controller checks the battery voltage. If the battery voltage is equal to or less than $60 \mathrm{~V}\left(V_{\mathrm{B}} \leq 60 \mathrm{~V}\right)$, the BESS is operated in the charging mode to absorb the surplus power. When the output power of $\mathrm{PV}$ is $2 \mathrm{~kW}$, the BESS goes to standby mode by changing the phase-shift angle to zero. As shown in Figure 4, there are two other conditions where the BESS goes on standby mode to protect the battery bank from being overcharged and overdischarged:

(i) When the battery voltage is less than $50 \mathrm{~V}$ and $P_{\mathrm{PV}}$ is less than $2 \mathrm{~kW}$

(ii) When the battery voltage is more than $60 \mathrm{~V}$ and $P_{\mathrm{PV}}$ is more than $2 \mathrm{~kW}$

Figure 6 presents the control system of the bidirectional isolated dc-dc converter. The battery is charged or discharged by the bidirectional isolated $\mathrm{dc}-\mathrm{dc}$ converter connected to the PWM converter. Accordingly, the control system determines the required power in order to regulate the PCC power at $2 \mathrm{~kW}$. The principal of this operation is based on (1).

The controller monitors $P_{\mathrm{PV}}, V_{\mathrm{D} 1}$, and $V_{\mathrm{B}}$. By using (1), $\delta$ will be obtained for both charging and discharging modes as follows: 


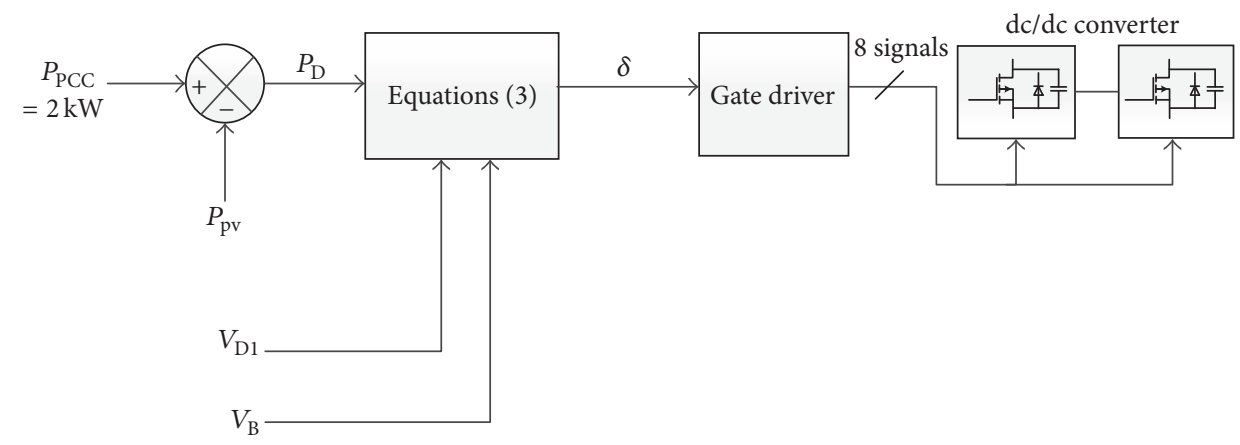

FIGURE 6: Phase-shift control of the bidirectional dc-dc converter.

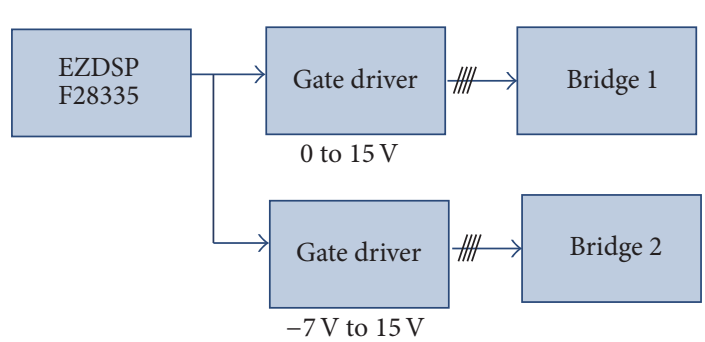

Figure 7: The overall controller connection of the dc-dc converter.

$$
\begin{gathered}
\text { Battery charging } \longrightarrow \delta=-\frac{\pi}{2}+\sqrt{\frac{\pi^{2}}{4}+\frac{\omega \pi L P_{\mathrm{D}}}{V_{\mathrm{D} 1} V_{\mathrm{B}} N}} \\
\text { Battery discharging } \longrightarrow \delta=\frac{\pi}{2}-\sqrt{\frac{\pi^{2}}{4}-\frac{\omega \pi L P_{\mathrm{D}}}{V_{\mathrm{D} 1} V_{\mathrm{B}} N}} .
\end{gathered}
$$

Equations (3) are used to calculate the desired phase-shift angle to achieve the required active power during charging and discharging modes of the battery [3].

Figure 7 illustrates the overall controller connection of the dc-dc converter. The specified phase-shift modulation frequency is $4 \mathrm{kHz}$ and the system clock frequency of the DSP F28335 is $150 \mathrm{MHz}$. The phase-shift angle is calculated in the DSP. The gate driver for HVS provides four signals of 0 to $15 \mathrm{~V}$, while the gate driver for LVS provides four signals of $-7 \mathrm{~V}$ to $15 \mathrm{~V}$ to avoid any accidental turn-on at the LVS because any parasitic inductance effect can be amplified with a higher current flow.

In order to minimize a high circulating current in the converter, a large mismatch between the transformer turns ratio and the voltage ratio of the HVS and LVS dc sides should be prevented. Therefore, a current controller is designed to regulate the voltage across the dc-link capacitor $C_{\mathrm{D} 1}$ using the three-phase $d-q$ synchronous reference frame control technique. Accordingly, the controller monitors $V_{\mathrm{B}}$ and keeps $V_{\mathrm{D} 1}$ at a level where the voltage ratio between $V_{\mathrm{D} 1}$ and $V_{\mathrm{B}}$ is close to the transformer turns ratio.

Figure 8 shows the control system of the PWM converter. The employed control system regulates the three-phase currents, $i_{\mathrm{a}}, i_{\mathrm{b}}$, and $i_{\mathrm{c}}$, to achieve unity power factor and to regulate the dc-link voltage $V_{\mathrm{D} 1}$ at a reference voltage equal to the transformer turns ratio multiplied by the battery voltage
TABLE 2: The gains of the three PI controllers.

\begin{tabular}{lccc}
\hline & $\mathrm{PI}_{1}$ & $\mathrm{PI}_{2}$ & $\mathrm{PI}_{3}$ \\
\hline Proportional gain $K_{p}$ & 0.1 & 0.9 & 0.9 \\
Integral gain $K_{i}$ & 5 & 0.01 & 0.04 \\
\hline
\end{tabular}

$V_{\mathrm{B}}$. The detailed derivation of the controller model has been presented in [8]. Table 2 presents the parameters of each PI controller. The parameters $K_{p}$ and $K_{I}$ are selected by trial and error method.

Figure 9 presents the implementation of the PWM converter control system that consists of three main blocks that are the sensors, the dSPACE DS1104 controller, and the PWM converter. Two-phase ac currents and ac voltages are sent to the ADC port and the third current and voltage are calculated in MATLAB/Simulink environment. The measured HVS dclink voltage is also sent to the ADC port. The carrier signal has a frequency of $10 \mathrm{kHz}$ and the modulation index is 0.9 . In addition, the dead time of the PWM converter is $1 \mu \mathrm{s}$. The SPWM signals are fed to the gate drivers to trigger the IGBTs.

\section{Experimental Results}

The experimental prototype and the control systems are built based on Figures 1 and 2. The parameters and gains are summarized in Tables 1 and 2, respectively. The BESS system is designed to supply a constant power of $2 \mathrm{~kW}$ into the grid at the PCC.

Figure 10 illustrates the dc operating waveforms of the BESS during changes of the PV output power. The step change is assumed to be from $2.5 \mathrm{~kW}$ to $2.8 \mathrm{~kW}$. The battery voltage is constant at $50 \mathrm{~V}$, and subsequently voltage $V_{\mathrm{D} 1}$ is regulated at $300 \mathrm{~V}$ by operation of the control system. The BESS is charged with $500 \mathrm{~W}$ when $P_{\mathrm{PV}}=2.5 \mathrm{~kW}$. Accordingly, the BESS is charged with $800 \mathrm{~W}$ when $P_{\mathrm{PV}}=2.8 \mathrm{~kW}$ to level the PV output power at the PCC. The transient response caused by the step change in power demand lasts for $70 \mathrm{~ms}$. This shows that the controller reacts fast and is feasible for PV output leveling.

Figure 11 shows the ac voltage and current waveforms at the HVS and LVS of the transformer when the BESS power transfer is changed from $-500 \mathrm{~W}$ to $-800 \mathrm{~W}$. There are changes to the phase-shift angle from $\delta=-13.82^{\circ}(-0.241 \mathrm{rad})$ 


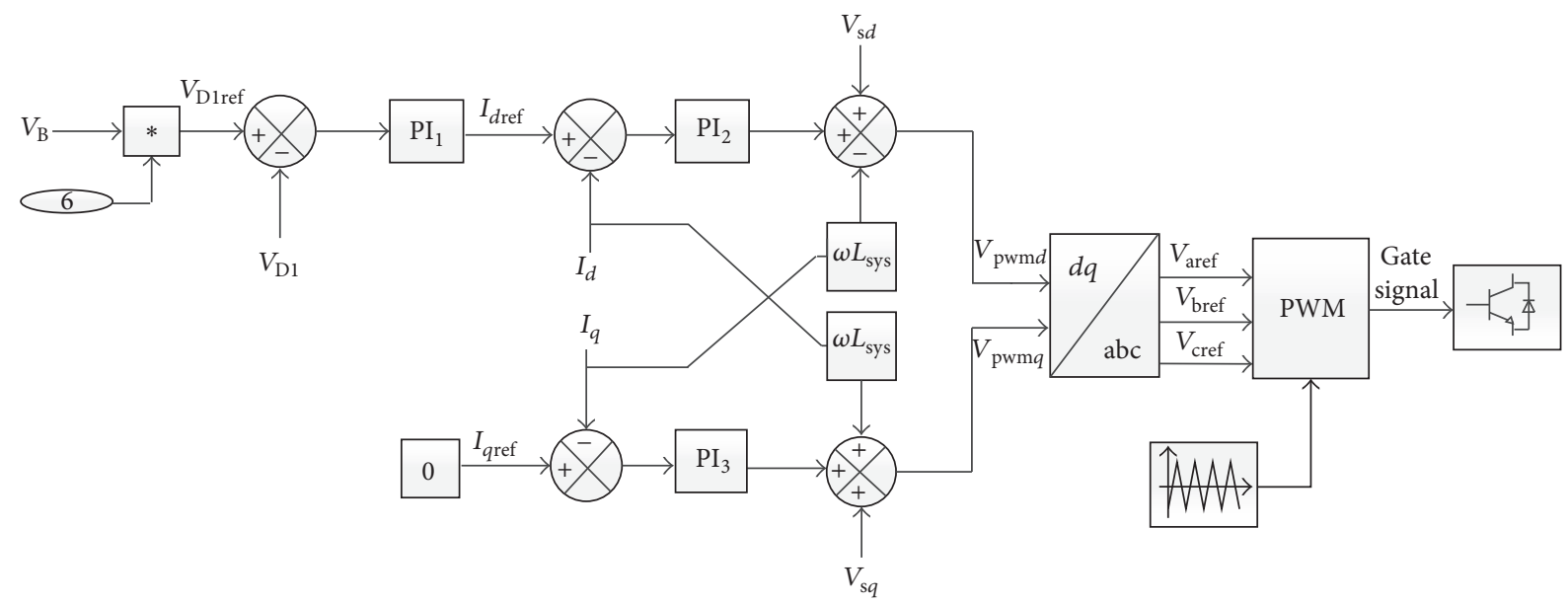

FIGURE 8: Current control of the PWM converter.

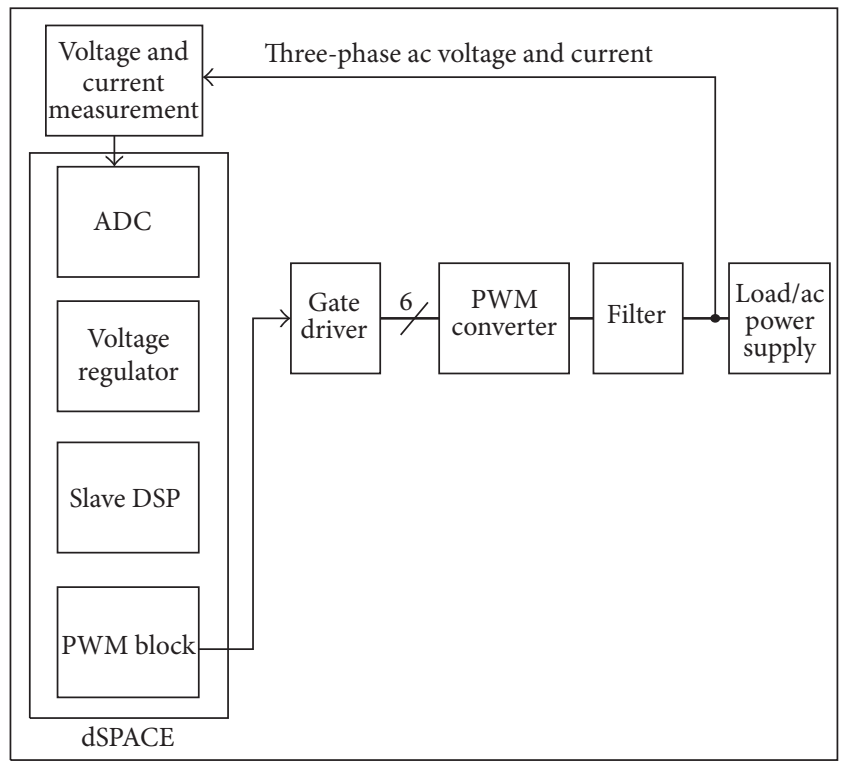

FIGURE 9: Block diagram of the dSPACE controlled PWM converter.

to $\delta=-21.5^{\circ}(-0.375 \mathrm{rad})$ during the change in power transfer requirement. The maximum voltages of transformer at the LVS and HVS are close to the transformer turns ratio, which are $50 \mathrm{~V}$ and $300 \mathrm{~V}$, respectively. The LVS have a so-called "flat top" current that reduces the rate of change of the current $i_{2}$ over the time interval of conduction. Thus, this will minimize the peak switching current, which leads to a lower switch turn-off overvoltage and improve converter efficiency.

Figure 12 presents the operation of the BESS when PV output power varies from $1.5 \mathrm{~kW}$ to $1 \mathrm{~kW}$. The battery voltage is constant at $60 \mathrm{~V}$ and voltage $v_{\mathrm{D} 1}$ is regulated at $360 \mathrm{~V}$ by operation of the control system. Initially, when $P_{\mathrm{PV}}=$ $1.5 \mathrm{~kW}, P_{\mathrm{D}}=500 \mathrm{~W}$ to regulate the power at the $P_{\mathrm{PCC}}$ to $2 \mathrm{~kW}$. When the PV output changes to $1 \mathrm{~kW}$, the BESS transfers $1 \mathrm{~kW}$ to the PCC to level the PV output. The transient response caused by the step change in power demand lasts for $100 \mathrm{~ms}$, and the peak of the transient current at the LVS is $22 \mathrm{~A}$.

Figure 13 shows that the magnitude of the phase-shift angle $\delta$ is increased from $8.63^{\circ}(0.151 \mathrm{rad})$ to $21.9^{\circ}$ (0.382 rad) during the discharging mode. Voltage $v_{2}$ leads $v_{1}$ in the discharging mode. Low-side transformer voltage is $60 \mathrm{~V}$ and high-side transformer voltage is $360 \mathrm{~V}$. This shows that the controller is able to regulate the voltage of HVS according to the transformer turns ratio. At the HVS, current $i_{1}$ is low and hence would not cause significant amount of switching loss. The LVS current appears as having the socalled "flat top." It reduces the rate of change of the current, $i_{2}$, over the time interval of conduction. Thus, this will minimize the peak switching current, which can cause a higher switch turn-off overvoltage, thus improving converter efficiency.

Figure 14(a) presents the three-phase ac current during the charging of BESS. The transient of the ac current lasted for $200 \mathrm{~ms}$. Figure 14(b) presents the ac voltage. The THD of voltage during charging of the $C_{\mathrm{D} 1}$ is around $2 \%$ and during the discharging operation of the dc-dc converter the THD is $1 \%$. The THD of grid current is measured with FLUKE 1735 Power Logger. The accuracy of this power logger is $\pm 0.2 \%$ of its full scale.

Figure 15 shows the enlarged ac voltage and current during the charging operation of the BESS at the power of $1 \mathrm{~kW}$ and battery voltage of $60 \mathrm{~V}$. The synchronized voltage and current waveforms show that the power factor is close to unity.

Figure 16 shows the converter efficiency when the BESS is operating in the charging and discharging modes. The efficiency of the dc-dc converter in the discharging mode is measured by choosing the LVS as the input and HVS as the output. On the other hand, the efficiency of the dc-dc converter in the charging mode is measured by choosing the HVS as the input and LVS as the output. At battery charging, the measured converter efficiency peaks at $95.4 \%$ at $P_{\mathrm{D}}=-400 \mathrm{~W}$. At battery discharging, measured converter 


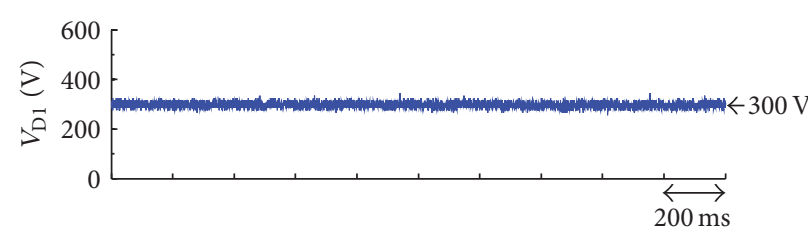

(a)

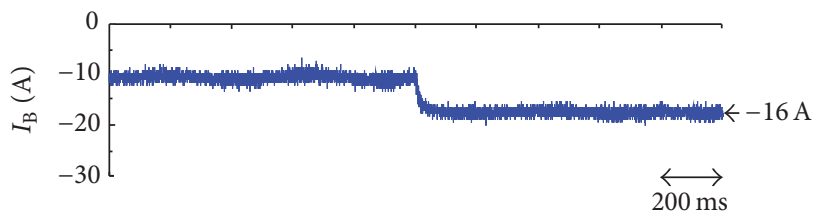

(c)

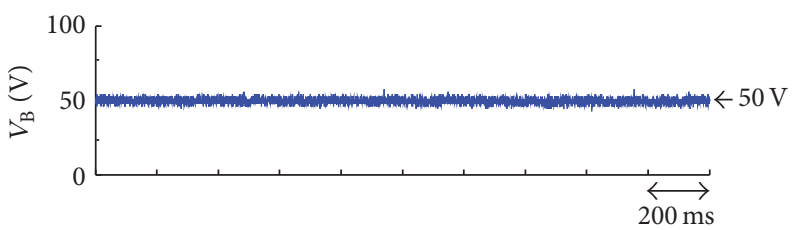

(b)

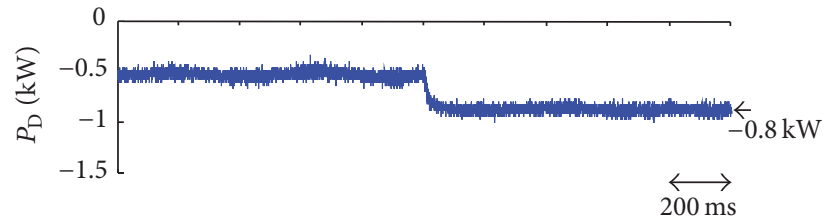

(d)

FIGURE 10: Experiment waveforms of the step change of PV output power from $2.5 \mathrm{~kW}$ to $2.8 \mathrm{~kW}$ at $V_{\mathrm{B}}=50 \mathrm{~V}$. (a) High-voltage side capacitor voltage. (b) Battery voltage. (c) Battery current. (d) BESS power.

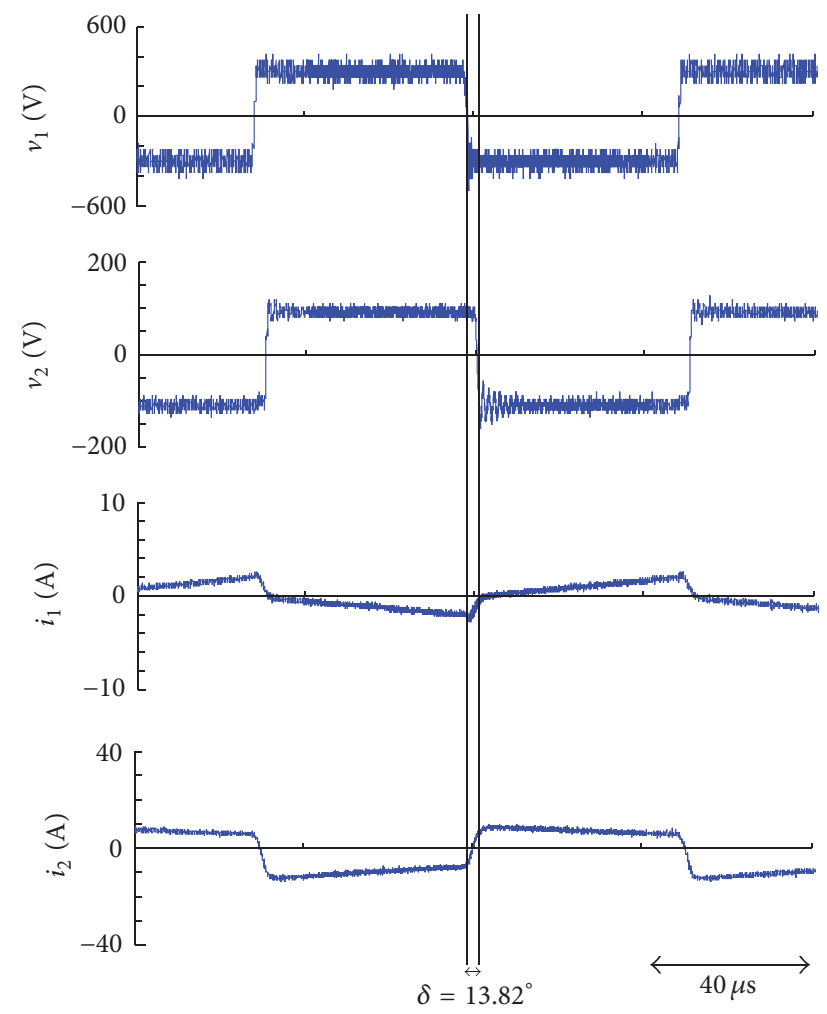

(a)

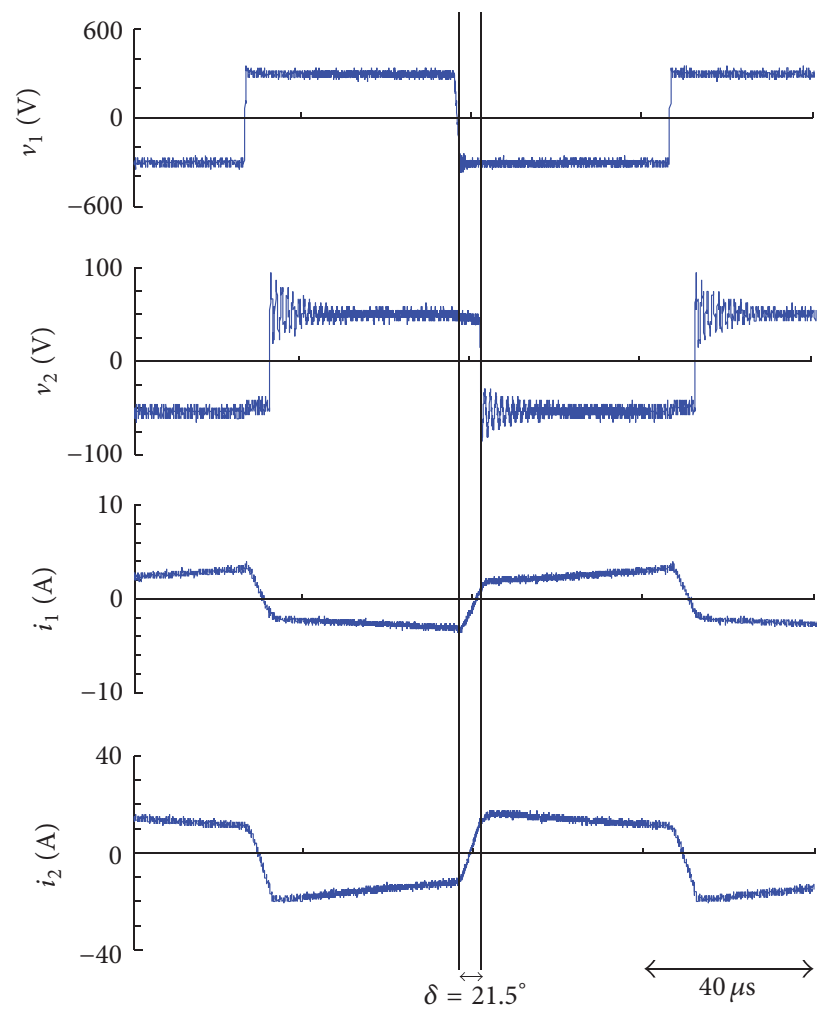

(b)

FIGURE 11: Experimental waveforms when the dc-dc converter is in charging mode. (a) $P_{\mathrm{D}}=-0.5 \mathrm{~kW}$. (b) $P_{\mathrm{D}}=-0.8 \mathrm{~kW}$.

efficiency peaks at $94.9 \%$ at $P_{\mathrm{D}}=600 \mathrm{~W}$. The battery voltage is $60 \mathrm{~V}$ for discharging mode and the battery voltage is $50 \mathrm{~V}$ for charging modes. Efficiency is low during low power transfer as the current is low.

At low current levels, the current could not reach the minimum required current for ZVS [4]. Thus, hard switching occurs. Furthermore, the efficiency increases when the current exceeds the minimum current for ZVS. At the rated power, the current increases, increasing the conduction losses and reducing the converter efficiency. The efficiency of the dc-dc converter is measured with YOKOGAWA WT1800 Precision Power Analyzer. The accuracy of this power logger is $\pm 0.2 \%$ of its full scale.

\section{Conclusion}

This paper proposed a $2 \mathrm{~kW}$ BESS for integration with a $\mathrm{PV}$ generator that is based on a bidirectional isolated dcdc converter and a PWM. The feasibility of the proposed system is verified via experimental results. The proposed 


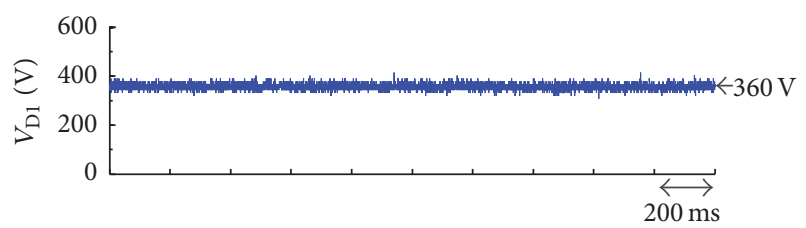

(a)

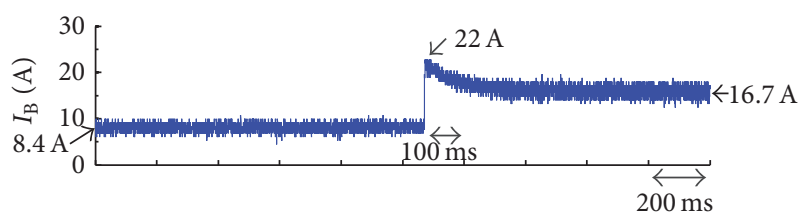

(c)

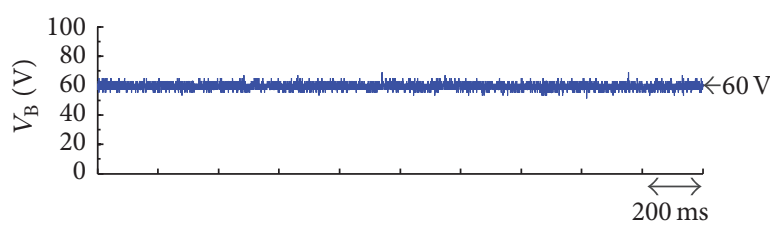

(b)

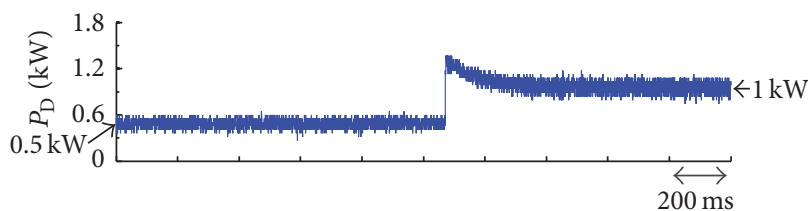

(d)

FIGURE 12: Experiment waveforms of the step change of PV output power from $1.5 \mathrm{~kW}$ to $1 \mathrm{~kW}$ at $v_{\mathrm{B}}=60 \mathrm{~V}$. (a) High-voltage side capacitor voltage. (b) Battery voltage. (c) Battery current. (d) BESS power.

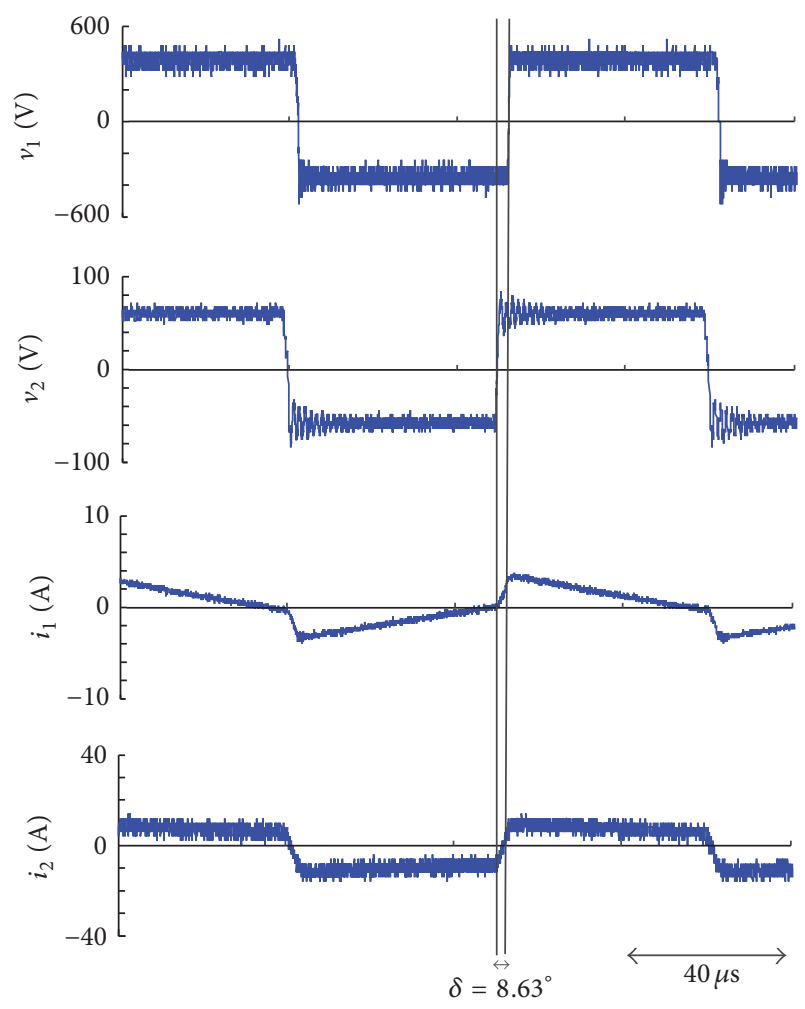

(a)

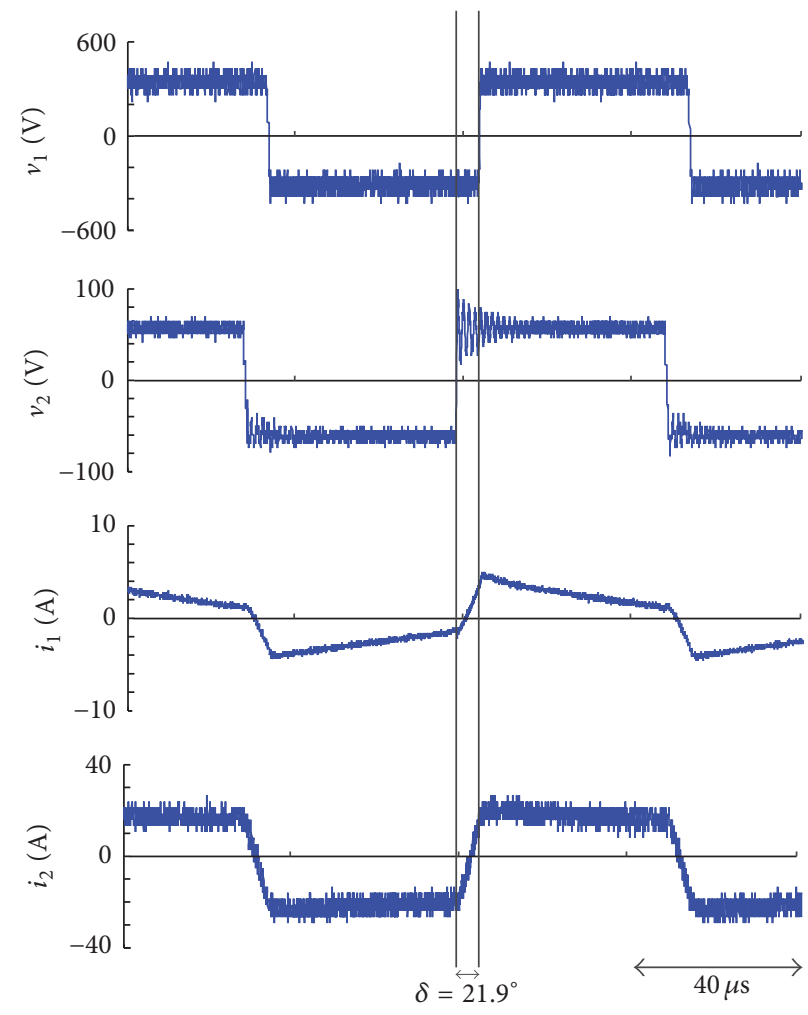

(b)

FIgURE 13: Experimental waveforms when the dc-dc converter is in discharging mode. (a) $P_{\mathrm{D}}=0.5 \mathrm{~kW}$. (b) $P_{\mathrm{D}}=1 \mathrm{~kW}$.

current controller regulates the voltage ratio of the HVS with LVS of the dc-dc converter equal to the transformer turns ratio. Accordingly, the switching losses are minimized to achieve an efficient power injection. The phase-shift controller manages the charging and discharging modes of the BESS to provide the required amount of power. The proposed BESS operates with unity power factor, injected current total harmonic distortion of less than $5 \%$, and fast dynamic response.

\section{Competing Interests}

The authors declare that there is no conflict of interests regarding the publication of this paper. 


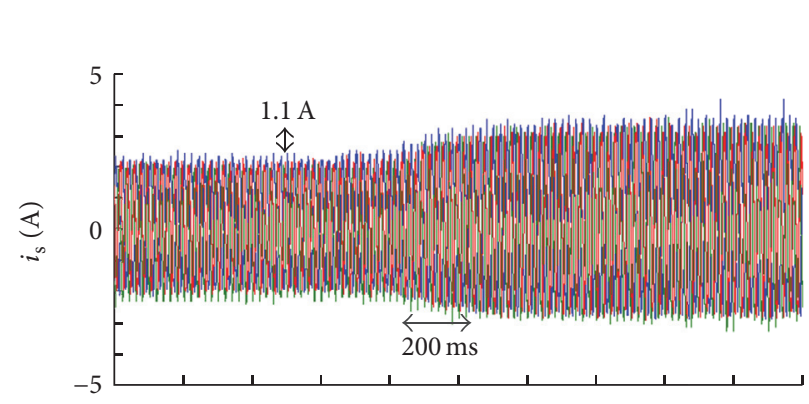

(a)

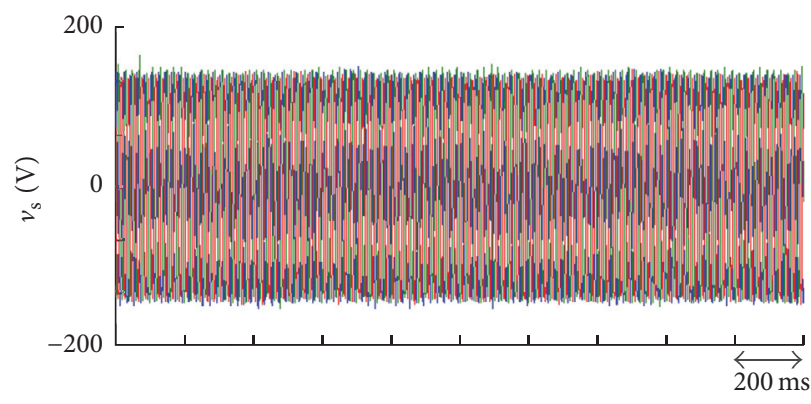

(b)

FiguRE 14: Variation of the charging mode from $-0.5 \mathrm{~kW}$ to $-0.8 \mathrm{~kW}$. (a) Three-phase ac current. (b) Three-phase ac voltage.

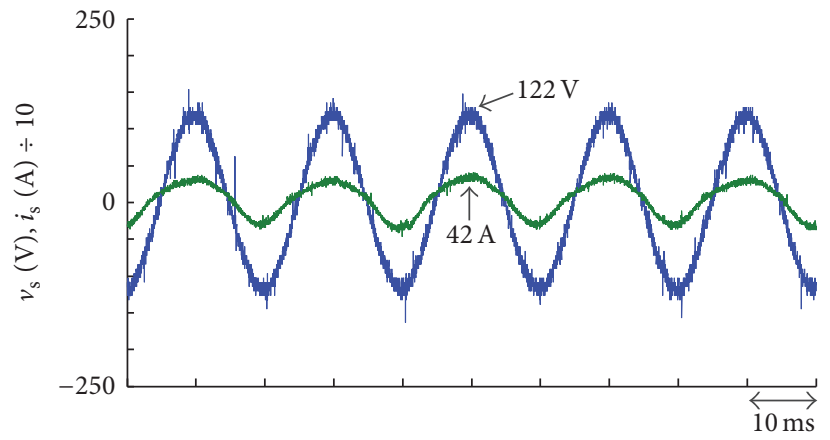

FIGURE 15: Ac voltage and current of phase-A during the charging operation of the BESS.

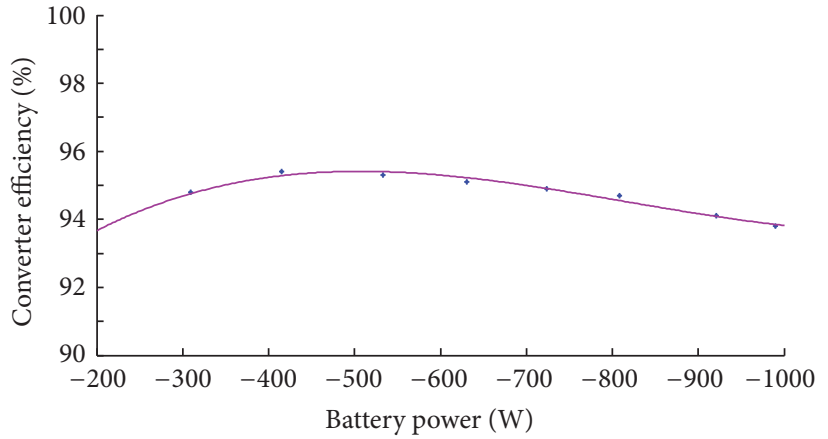

(a)

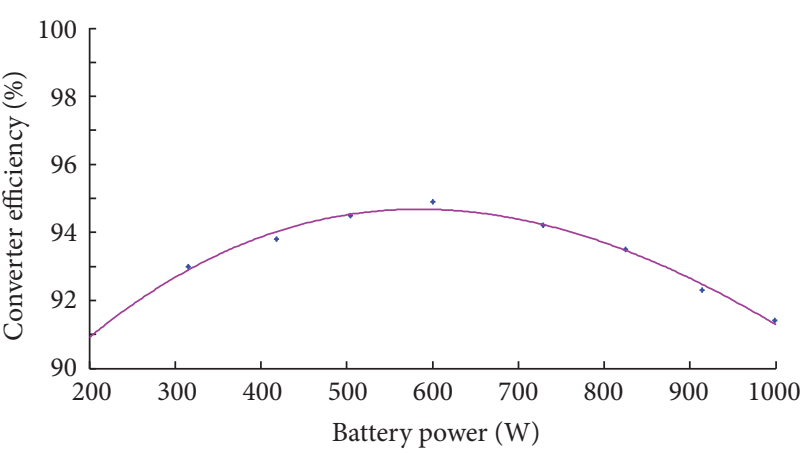

(b)

FIgURE 16: Measured dc-dc converter efficiencies. (a) Battery charging. (b) Battery discharging.

\section{Acknowledgments}

The authors wish to thank the Ministry of Higher Education (MOHE) and Universiti Tenaga Nasional for the financial support through FRGS/1/2012/TK07/UNITEN/02/11 and Internal Grant no. J510050610, respectively.

\section{References}

[1] Y. Yang, P. Enjeti, F. Blaabjerg, and H. Wang, "Wide-scale adoption of photovoltaic energy: grid code modifications are explored in the distribution grid," IEEE Industry Applications Magazine, vol. 21, no. 5, pp. 21-31, 2015.

[2] J.-S. Lai, B.-M. Song, R. Zhou, A. Hefner Jr., D. W. Berning, and C.-C. Shen, "Characteristics and utilization of a new class of low on-resistance MOS-gated power device," IEEE Transactions on Industry Applications, vol. 37, no. 5, pp. 1282-1289, 2001.

[3] N. M. L. Tan, T. Abe, and H. Akagi, "Design and performance of a bidirectional isolated DC-DC converter for a battery energy storage system," IEEE Transactions on Power Electronics, vol. 27, no. 3, pp. 1237-1248, 2012.

[4] S. Inoue and H. Akagi, "A bidirectional isolated DC-DC converter as a core circuit of the next-generation mediumvoltage power conversion system," IEEE Transactions on Power Electronics, vol. 22, no. 2, pp. 535-542, 2007.

[5] H. Akagi, T. Yamagishi, N. M. L. Tan, S.-I. Kinouchi, Y. Miyazaki, and M. Koyama, "Power-loss breakdown of a 750$\mathrm{V}$ 100-kW 20-kHz bidirectional isolated DC-DC converter using SiC-MOSFET/SBD dual modules," IEEE Transactions on Industry Applications, vol. 51, no. 1, pp. 420-428, 2015. 
[6] N. M. L. Tan, S. Inoue, A. Kobayashi, and H. Akagi, "Voltage balancing of a 320-V, 12-F electric double-layer capacitor bank combined with a $10-\mathrm{kW}$ bidirectional isolated DC-DC converter," IEEE Transactions on Power Electronics, vol. 23, no. 6, pp. 2755-2765, 2008.

[7] R. W. A. A. De Doncker, D. M. Divan, and M. H. Kheraluwala, "A three-phase soft-switched high-power-density DC/DC converter for high-power applications," IEEE Transactions on Industry Applications, vol. 27, no. 1, pp. 63-73, 1991.

[8] R. Singh, S. Taghizadeh, N. M. L. Tan, and J. Pasupuleti, "Battery energy storage system for PV output power leveling," Advances in Power Electronics, vol. 2014, Article ID 796708, 11 pages, 2014. 


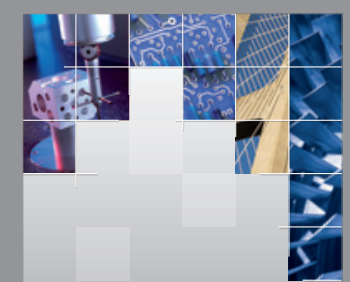

\section{Enfincering}
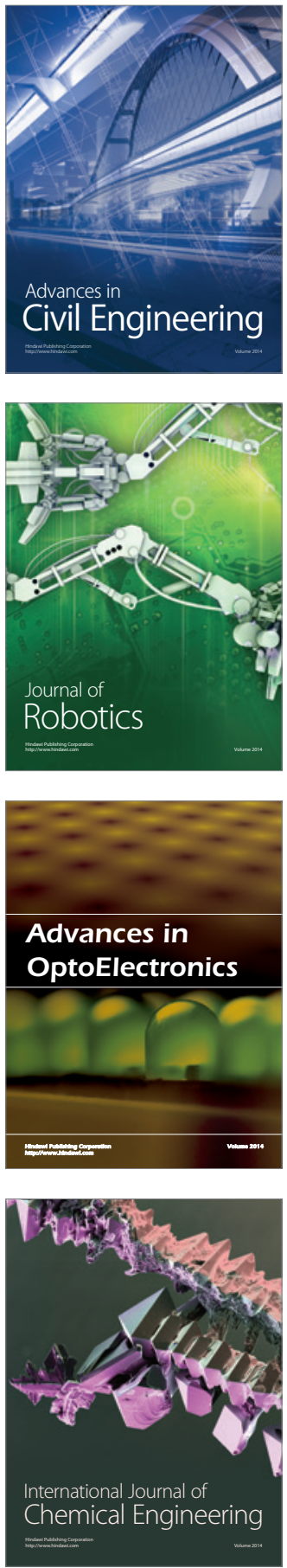

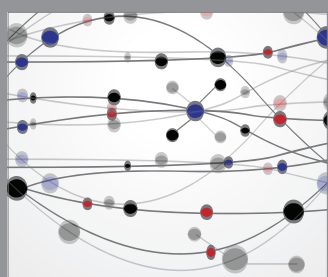

The Scientific World Journal

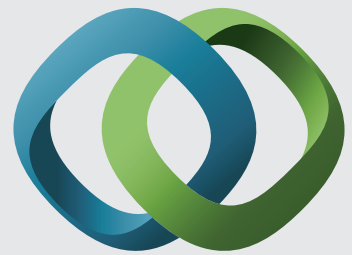

\section{Hindawi}

Submit your manuscripts at

https://www.hindawi.com
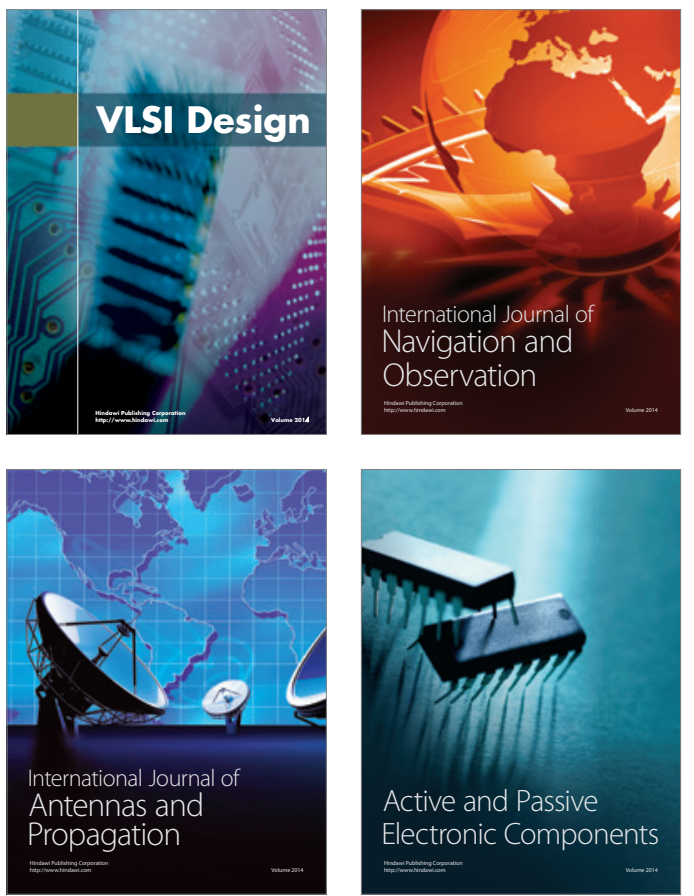
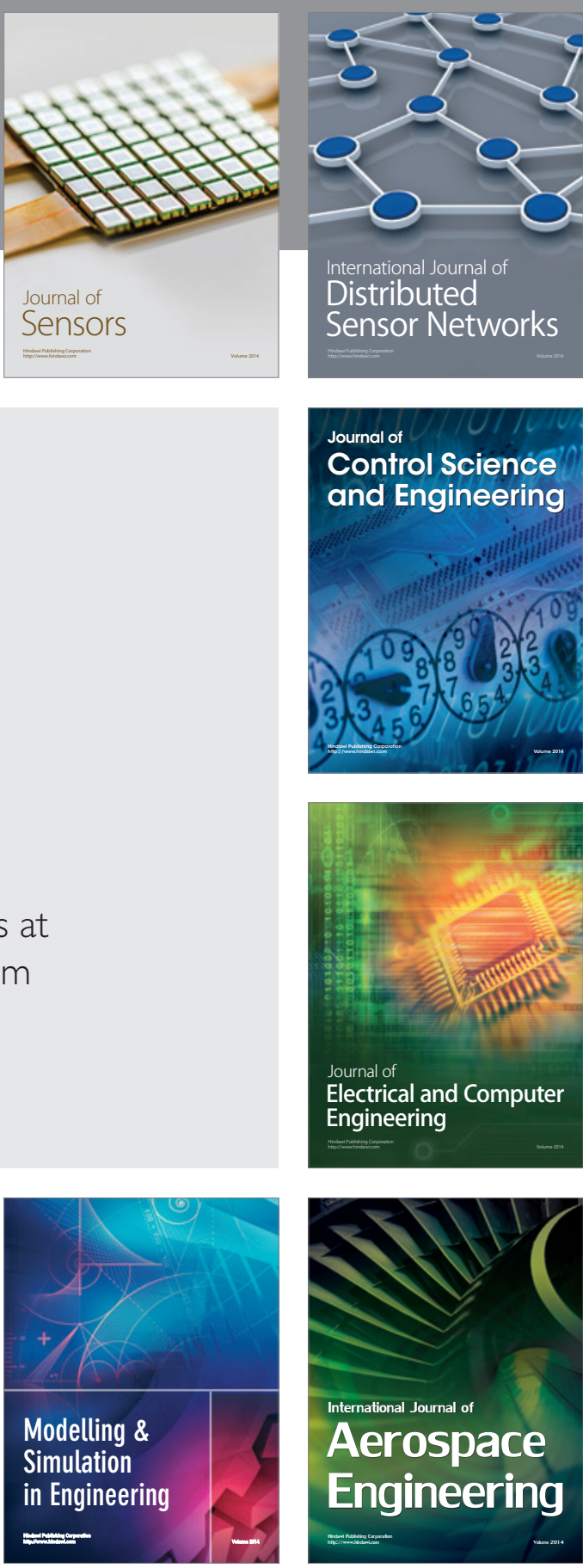

International Journal of

Distributed

Sensor Networks

$-$

Joumal of

Control Science

and Engineering
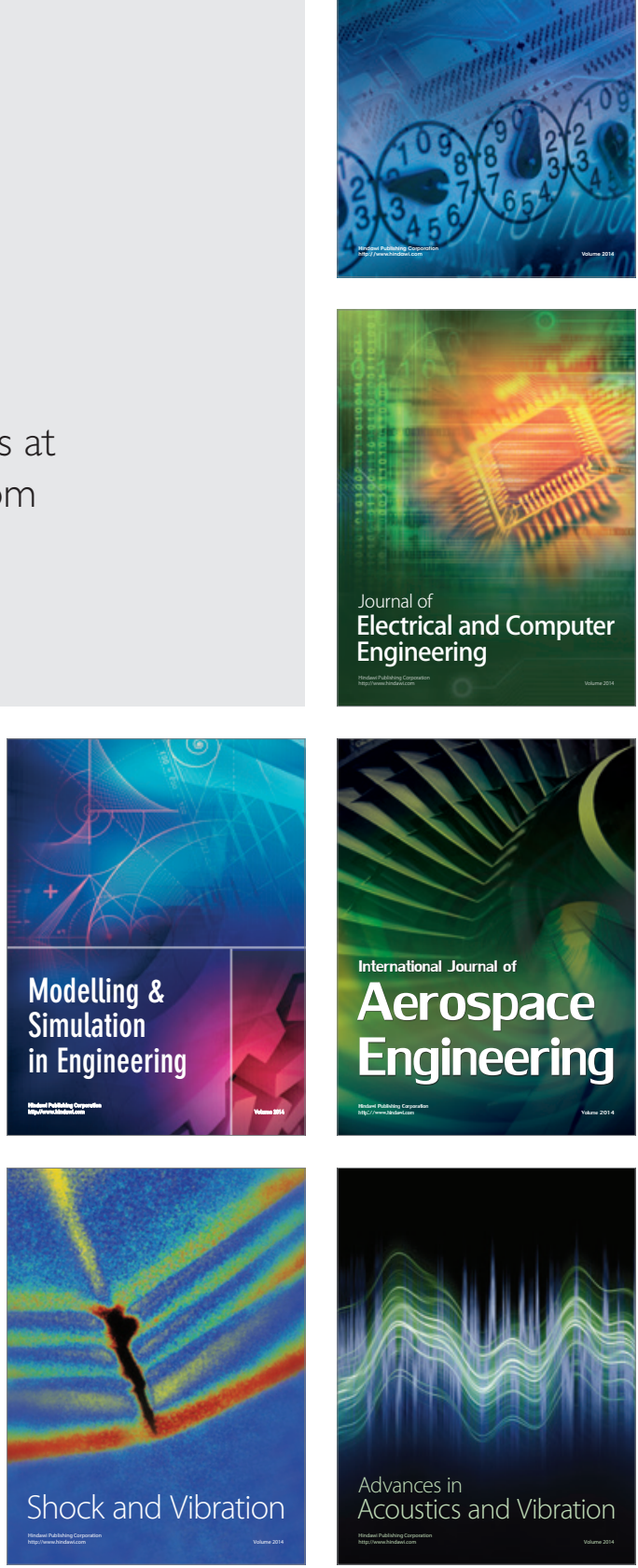